\title{
ResearchOnline@JCU
}

This is the author-created version of the following work:

Lowrie, Daniel, Ray, Robin, Plummer, David, and Yau, Matthew (2018) Exploring the contemporary stage and scripts for the enactment of dying roles: a narrative review of literature. Omega: Journal of Death and Dying, 76 (4) pp. 328-350.

Access to this file is available from:

https://researchonline.jcu.edu.au/46447/

Accepted Version may be made open access in an Institutional Repository without embargo.

Please refer to the original source for the final version of this work: 


\section{Exploring the contemporary stage and scripts for the enactment of dying roles: A narrative review of the literature}

\section{Authors:}

Daniel Lowrie ${ }^{a}$, Robin Ray ${ }^{b}$, David Plummer ${ }^{c}$, Matthew Yau ${ }^{\mathrm{d}}$

\section{Author Details:}

Daniel Lowrie $^{a}$

${ }^{a}$ College of Healthcare Sciences, James Cook University, James Cook Drive, Douglas, Australia

Phone: (07)4781 5951

Email:daniel.lowrie@jcu.edu.au

Robin Ray ${ }^{b}$

${ }^{b}$ College of Medicine and Dentistry, James Cook University, James Cook Drive, Douglas, Australia

Phone: (07) 47814474

Email: robin.ray@jcu.edu.au

David Plummer ${ }^{c}$

${ }^{c}$ School of Medicine, Griffith University Gold Coast campus, Southport, Australia

Phone: (07) 56780883

Email:d.plummer@griffith.edu.au

Matthew Yau ${ }^{\mathrm{d}}$

${ }^{d}$ Department of Rehabilitation and Social Sciences, Tung Wah College, Shantung Street, Hong Kong

Phone: (852) 34686670

Email:matthewyau@twc.edu.hk

Corresponding Author: Daniel Lowrie

Acknowledgements:

Nil

Funding and grant-awarding bodies: No funding or grant-awarding bodies

Key Words: Dying roles, death, dying, role change, palliative care 


\title{
Exploring the contemporary stage and scripts for the enactment of dying roles: A narrative review of the literature
}

\begin{abstract}
This narrative review explores the literature regarding the drama of dying from several academic perspectives. Three key themes were identified including: 'The impact of blurred boundaries on roles and transitions', 'The orchestration of death and dying through time' and 'Contemporary dying and new machinery of control'. The review reveals the manner in which tightly scripted dying roles serve the needs of the living to a greater extent than those of the dying, by ensuring the depiction of both dying and death as phenomena which have been brought under the control of the living, thereby countering death anxiety. An incongruence between the actual experience of dying and contemporary dying scripts is also highlighted. The authors argue that this incongruence is hidden from the broader societal audience through the maintenance of a dying role that demands serenity and acceptance, thus downplaying or even hiding the actual end-of-life experiences of the dying themselves.
\end{abstract}

\section{Research Highlights}

- Dying roles significantly shape the lived experience of people at end of life. 
- Dying roles are, and have always been, socially constructed.

- Dying roles serve the needs of the living.

\section{Background - roles and role change at end-of-life}

Roles serve an important function within society by offering a set of norms to guide people's behaviours and attitudes in particular social situations (Turner, 1990). Roles also contribute significantly to an individual's sense of personal identity and, in doing so, act as a key juncture between an individual and the society in which he or she lives (Lynch, 2007). Role performance is not shaped by individuals in isolation, but rather as an interactive and negotiated process between various actors (Lynch, 2007; Turner, 1956). During the course of their lives, individuals will transition into and out of a variety of roles. Role transitions frequently accompany key life milestones (such as puberty, marriage or retirement) and will be marked by a variety of rituals and symbols to indicate the perishing of an old self and subsequent birth of the new (van Gennep, 1909/1960). Role change thus serves as a powerful mechanism of social control by ensuring the transition from one set of social scripts to another. Role change at end of life acts in the same way by enabling the relinquishment of a previous social status and the emergence into a new role for dying people and those around them. In a sense, the 'pronouncement' and subsequent social recognition of dying (and, at a later stage, death) trigger the orchestration of sequential acts in a broader drama of dying (Goffman, 1959). 
The drama of dying represents life's final act. Knowledge of this drama, therefore, might reasonably be regarded as critically important. Useful insights have been offered in research by ParkerOliver (2000) who presented a dramaturgical analysis of hospice care in directing the transition from the 'sick role' to the 'dying role' for people approaching end of life. The findings of this study outline the key entry points, scenes, scripts and props that accompany dying and highlight the important function of the hospice community in facilitating the enactment of the dying role. More recently, Emanuel, Bennett, and Richardson (2007) examined the dying role from the perspective of role theory. They describe the dying role as having practical, relational and personal elements which, while interactive in nature, are in essence distinguishable from each other. The analyses within both of these papers consists of a fusion of the literature regarding role enactment and palliative care, framed in the context of the authors' clinical experience. It is noteworthy that both also emphasize the centrality of health professionals in nurturing an awareness of the dying role among individuals nearing end of life.

This narrative review of the literature builds on these existing perspectives regarding the stage and scripts that shape contemporary dying roles, by exploring the published literature across a broad variety of academic fields. In doing so, it offers new insights into numerous factors which influence the enactment of the drama of dying and, in turn, the experience of dying for both people approaching end of life and those around them. 


\section{Approach to Searching the Literature}

The research team undertook a literature search using Medline, CINAHL, PsychInfo and Scopus databases. Keywords were used to identify literature which addressed the concepts of "roles", "experience" or "change" and "death", "dying" or "palliative care". The specific search terms were expanded and customised for each database using Medical Subject Headings (MeSH) (Medline), 'Suggest Search Terms' (CINAHL) and 'thesaurus' (PsychInfo). Scopus was searched using the combination of search terms identified from each of the other databases. A detailed breakdown of specific search terms and number of hits retrieved within each database is included within Appendix 1.

A total of 5170 articles were identified. The principal researcher (first author) initially screened these articles based on their titles and abstracts (and removed duplicate articles). From this first screening process 180 articles were flagged by the principal researcher as potentially relevant and full-text copies sourced. The principal researcher then undertook a more detailed appraisal of the remaining papers in order to identify articles of particular pertinence to the topic. Articles were included if they focused on the experience or understanding of dying or specifically addressed dying roles. NonEnglish language articles and articles which focused on only one aspect of dying (such as symptom management) were excluded. No limits were placed on date of publication. Following this secondary screening process, a total of 33 articles were found to be relevant for inclusion in the narrative review. 
Weekly alerts were set up for each of the above database searches to ensure that the examination of the literature remained current. As well as this, additional references (including seminal textbooks) were sourced by the principal researcher through reference mining and the use of the 'cited by' function for key articles. This process was continued until no new relevant references were identified. Through these additional processes a further 45 sources of literature were added. The combined total of 78 sources of literature form the basis of the construction and analysis of the key themes within this narrative review paper.

While the search has been undertaken in a systematic manner, the use of a framework such as PRISMA to structure the review was not considered suitable. This is because the research question is exploratory in nature and will not, therefore, generate items of evidence that can be compiled and compared. Instead, the goal is to examine a wide range of literature from several academic fields in order to develop a broad understanding of the drama of dying within contemporary society. Identification of key themes within this narrative review occurred iteratively and involved the principal researcher engaging in a preliminary reading of each literature source to examine the key ideas within it, with subsequent readings undertaken in order to evaluate the implications of these ideas, specifically in relation to the context of dying roles. Themes were initially identified by the principal researcher and then refined over several meetings of all members of the research team. This process helped to promote analytical rigour and ensure that relevance to the central topic of dying roles was maintained. In undertaking the steps 
described above, three broad themes were identified by the research team, namely: 'The impact of blurred boundaries on roles and transitions', 'The orchestration of death and dying through time' and 'Contemporary dying and new machinery of control'. Each of these themes forms a section of this narrative review.

\section{The impact of blurred boundaries on role transitions}

\section{Living, dying and death}

In order for the recognition and subsequent enactment of dying roles to occur, recognisable boundaries demarcating living, dying and death are required. While, at face value, the recognition of both dying and death may appear conceptually straight-forward, in many circumstances there is ambiguity regarding their timing and nature. For example, debate exists as to whether an irreversible coma with absent brain stem reflexes constitutes death or whether death should instead be defined as the complete loss of critical functions of a body (Beecher, Adams, \& Barger, 1984; Bruno, Ledoux, \& Laureys, 2009). The advent of new technologies to artificially extend life or initiate brain repair serve to further complicate this picture, (Hart, Sainsbury, \& Short, 1998) foregrounding a philosophical dimension to what might otherwise be perceived as a biomedical debate (Bruno et al., 2009).

The boundaries separating the worlds of the living and the dead become further blurred when viewed from a social perspective. Howarth (2000) provides the example of the social death of an elderly woman with senile dementia who is no longer recognisable to 
her loved ones, having long since lost the roles and relationships that shaped her identity. While biologically alive, this woman may already be considered deceased from the perspective of her loved ones, existing in a state of extended liminality in which she is neither socially alive nor physically dead. Conversely, Howarth (2000) describes numerous situations in which individuals may be considered biologically dead but kept socially alive by others. For example, it is very common for people to engage in conversations with deceased loved ones or to nurture their ongoing biographies through celebrations of key milestones, anniversaries, birthdays and 'deathdays' or to maintain shrines or memorials for persons who have died (Howarth, 2000).

Given the degree of ambiguity surrounding the nature of death, it is perhaps not surprising that the construct of dying also lacks conceptual clarity. This is because dying, like death, is not only a medical phenomenon but also an existential, psychological and social experience (Kellehear, 2009a). At its heart, therefore, debate around both the timing and nature of dying is one which is philosophical in nature and reflective of the multiple significances attributed to different forms of dying. An examination of the different facets of this debate is critical to understanding role change among the dying since it exposes the manner in which different perspectives can influence beliefs as to who can be regarded as dying and how dying is thought to occur.

A useful starting point is to note that dying and living need not be mutually exclusive states, nor is dying the opposite of living. For example, logic seems to suggest that it is necessary for a dying 
person to be alive; otherwise, they are not dying, but dead (Scarre, 2009). Certainly, the ethos of the palliative care movement emphasises the principle of living well while dying, pointing to a conceptual understanding of living and dying as overlapping states of being (Palliative Care Australia, 2005; World Health Organisation, 2007). Further to this, there are some who argue that, given the inevitability of death, all people are, in fact, dying from the day they are born (Bowman, 1965), while others contend organisms undergo a significant period of maturing before they would normally be considered to be in a state of dying (Scarre, 2009).

Such points of theoretical division are very important and largely unexplored when considered in the context of dying roles, particularly with regard to status changes. If dying is simply considered to be a state in which individuals are cognisant of their own mortality, then many of the functions and behaviours surrounding dying roles should be observable in people for whom no formal 'pronouncement' of dying has been offered. In essence, therefore, strong similarities between core functions of 'living roles' and 'dying roles' would be present. If this were to be the case, then as death draws nearer, individuals would experience an escalation (and in some cases an enrichment) of key aspects of what is an already familiar dying role rather than a transition into an entirely new status. However, if entry to the dying role represents the transition of a dying person into a new and unfamiliar status, then the emphasis on the point at which dying is recognised, as well as the rites of passage, functions and experience of the dying role, take on a different significance. 
A further possibility is that dying may not be a status in its own right, but rather representative of the liminal phase between the statuses of living and dead (Froggatt, 1997; Seale, 1998). Turner (1974), building on the earlier work of anthropologist Arnold van Gennep (1909/1960), described the rites of separation and symbolic behaviours that accompany the liminal phase between an individual's separation from one status and eventual incorporation into another. According to Turner (1974), within this liminal phase, the person undergoing a status transition will be cut off from wider societal structures, entering into a realm in which normal social rules and hierarchies do not exist. As such, an 'anti-structure' will be created, offering a sacred space within which transitions can occur (Turner, 1974). In her examination of the rites of passage within hospice culture, Froggatt (1997) likens hospice care to the institutional embodiment of liminal space in which status transitions occur, pointing to elements of the hospice environment that allow the withdrawal from normal modes of social action and support the negotiation of the boundaries between life and death.

\section{Managing boundaries - the declaration of dying and death}

The potential for ambiguity arising from the lack of an obvious point in time in which dying may be regarded to have commenced is, to a large extent, overcome by one of the key actors in the drama of dying, this being the person who pronounces dying. In recent times this role has been predominantly enacted by medical professionals or (in the case of state executions) judges. These actors are responsible for setting in motion the opening act in the drama of dying through a declaration that death is near and, in doing so, authorising the 
transition into a new social status of 'a dying person'. Once this occurs, social systems will organise around this new status and orchestrate the process.

The need for such actors lays bare the social sanctioning of dying, thus adding weight to the argument that particular forms of dying are considered more legitimate than others (Kellehear, 2009b) depending on the prevailing values and beliefs particular to the culture (and time) in which they occur (Seale, 1998). Consequently, understandings of dying become filtered through a specific, but limited, lens which, in turn, exerts a powerful influence in shaping health policy, clinical practice, research and public perception (Kellehear, 2009b). This narrowed perspective serves a valued (although arguably unhelpful) societal function in shaping a public perception of death and dying as phenomena that are both predicable and manageable and thus under the control of the living.

The consequence of such a narrowed perspective is the creation of a dying underclass to whom a socially sanctioned status of dying is rarely afforded on the basis that it is not easily recognised and / or controlled by medical professionals. In recent times, this dying underclass has been composed of people who experience less predictable, non-linear or non-illness related dying processes as a result of causes such as old age, dementia, poverty, homelessness and suicide (Hayslip, 2003). Individuals among these groups may not experience dying roles due to a lack of awareness and acceptance of dying among both themselves and those around them (Field, 1996). Unsurprisingly, perhaps, very little is known about the experience of role change in people who undergo these socially marginalised forms 
of dying. For such individuals, established models for understanding role transitions which emphasise clear boundaries and permanent, socially sanctioned status changes such as that of van Gennep (1909/1960), may not be easily applied.

\section{The orchestration of death and dying through time}

Experiences of death and dying today reflect processes that have developed over thousands of years, evolving in step with cultural and social norms of the time (Kellehear, 2007b). These cultural and social norms have exerted a powerful influence over elements of the dying process such as the location and setting of death as well as the expected roles, responsibilities and associated behaviours of both people who are dying and those around them (Elias, 1985; Walter, 1994). Analyses of death and dying through history, therefore, provide a useful background for examining modern practices by shedding light on a dying process that, while constantly evolving, has remained socially constructed and controlled since the dawn of humanity.

\section{Dying roles among early humans}

In his “A Social History of the Dying” Kellehear (2007b) argues that the ceremonial burial practices of early humans approximately 30,000 to 50,000 years ago, such as the elaborate dressing of the deceased and the provision of grave goods, point to a belief in a postdeath 'dying journey' for which such valuable commodities would be essential if it were to be undertaken successfully. Kellehear's (2007b) analysis is an important one as it offers the earliest clear 
example of the social construction of both dying and dying roles among early humans. For these people, knowledge of and beliefs concerning dying would have been shaped almost entirely through their participation in the post-death rites of passage provided to other social group members who had died before them. In witnessing these rituals, they would have developed an understanding of dying as a process which is both reliant on and controllable by the efforts of the social group surrounding the dying individual. Furthermore, these ceremonies will have also served a social function by formalising a point of role relinquishment by the deceased, thus allowing others to fill the role void he or she leaves behind (Walter, 2003). The role of the dying, therefore, becomes somewhat secondary to the roles of those around them in order to maintain the stability of social structures needed by the living. In essence, this marks the beginning of a socially sanctioned dying process, both controlled by and serving the interests of the living, which has been repeated throughout history.

\section{Pre-modern dying roles}

It is through this lens of socially sanctioned dying that a tension between the notions of autonomy and familiarity associated with the 'tamed' deaths of medieval times, famously proposed by French historian Phillippe Aries (1974, 1981), becomes apparent. While, at least at face value, the more central role of individuals with regard to the processes surrounding their own dying would seem to point to greater autonomy, realistically the choices which were afforded to the dying individual will have been shaped and sanctioned according to the familiar prevailing social norms of the time. For example, 
during the period of time that formed the basis of Aries' $(1974,1981)$ pre-modern analysis, socially approved dying scripts within Western societies reflected the dominance of the Christian church. A morally good death was thus one which was Christ-like in nature and, as such, social expectations were that the dying individual would avoid temptations such as despair, loss of faith or spiritual pride (Walters, 2004). Steps to ensure the achievement of a morally good death went as far as the creation of illustrated scripts for dying known as the 'ars moriendi' (the art of dying) which were developed to guide the dying person and those around them towards the accomplishment of a saintly death by avoiding any behaviours that may steer him or her from this path (Gittings, 2009).

\section{Modern dying roles}

The rise of the natural sciences and medical positivism and the subsequent relegation of religion, philosophy and humanism during the $18^{\text {th }}$ century ushered in new key actors and significantly altered scripts in the drama of dying. During this time, powerful professional groups, particularly medicine, established control over the dying process (Hart et al., 1998). Given the focus of biomedicine on curing illness, dying came to be framed as problematic and, therefore, control over dying centred on death prevention (or more realistically, postponement). This paved the way for the engineering of death and dying into a secularised, technical and depersonalised affair that was managed by professional and bureaucratic institutions, shrouded from the view of the majority of the population and, indeed, often hidden from the dying themselves (Glaser \& Strauss, 1965, 1968). 
Many argue that the hidden, lonely and impersonal nature of modern dying was clearly exemplified by the way in which dying people were managed both prior to and then after death. Concerns surrounding the medicalisation of dying were brought to popular attention by Elizabeth Kubler-Ross (1969) who bemoaned modern dying as having become "gruesome, lonely, dehumanised and mechanical" (Kubler-Ross, 1969, p. 6). Others point to the relocation of the elderly and the dying to nursing homes and hospices as a social mechanism to assist in removing thoughts of death and the dying from public consciousness (Stephenson, 1985). Elias (1985, p. 23) highlights the "screening off" of the dying from others (particularly children), describing a sense of embarrassment experienced by the living when in the presence of dying people. Processes such as these resulted in dying people finding themselves bit-part players at best or, at worst, roleless in the narrative of their own death.

\section{Contemporary dying and new machinery of control}

The emergence and subsequent growth of the modern hospice movement since the late 1960s, the increasing focus on death in films, plays and novels and the debate around euthanasia have all contributed to a gradual rekindling of public discourse of death (Doka, 2003; Walters, 2004). It should be noted, however, that 'the revival of death', as described by Walter (1994) really refers only to illness-related death, while almost all other forms of death remain hidden and unrecognised (Field, 1996; Kellehear, 2009b). Regardless, death is no longer the taboo subject that it once was 
(Bingley et al., 2006; Seale, 1998; Walters, 2004). Furthermore, the rise of individualism and the perceived right to autonomy as a moral prerogative within Western society have resulted in challenges to established medical hegemony, bringing openness about diagnosis, prognosis and patient choice to the forefront of care (Field, 1996; Seale, 1998). At face value at least, these changes would point to a renewed and more self-directed role for the dying individual in regard to his or her own death. However, as has been the case throughout history, new mechanisms of control significantly curtail the scope in which the dying roles of dying people and their families can be enacted.

\section{The rise of palliative care}

The availability and provision of palliative care services are often highlighted as serving a critical function in ensuring quality end-oflife care. Good, contemporary evidence exists, demonstrating the benefits of palliative care services in improving patient quality of life (Higginson, Costantini, Silber, Burman, \& Edmonds, 2011; Lyons \& Bakitas, 2009; Temel et al., 2010; Zimmermann et al., 2013).

Palliative care services include among their stated aims a commitment to patient (and family) centredness, recognition of individual uniqueness and delivery of collaborative, holistic care, all of which, at least theoretically, should foster an approach to dying that is markedly more open, personalised and humanistic than that of the modern era (Dahlin, 2013; Palliative Care Australia, 2005; World Health Organisation, 2007). Recent survey data of the attitudes of 47 internal medicine doctors and 39 hospice nurses would seem to support this position, with 100 percent of respondents indicating a 
belief that hospice care gives patients some autonomy and 95 percent agreeing that it provides patients with a sense of control (Bakanic, Singleton, \& Dickinson, 2016).

The rise and growth of palliative care has not, however, been without its critics. Numerous authors have pointed to an entrenched state of bureaucratization within hospices as contributing to considerable homogeneity and routinisation in the design and delivery of palliative care services, consequently compromising the implementation of individualised care (Floriani \& Schramm, 2012; James \& Field, 1992; McGrath et al., 2005; Seale, 1998).

The expanded scope and medicalisation of palliative care has also been a source of some criticism. As early as two decades ago, Walter (1994) asserted that palliative care had metamorphosed into little more than a façade behind which modern medical practice continued to control the dying process, under the auspices of an 'imagined tradition' of holistic, person-focussed, non-hierarchical care. Walter (1994) argued that this change was clearly observable through the rise of the medical sub-specialty of palliative medicine and consequent subjugation of other professions and lay workers within palliative care. He further suggested that this transition had brought with it an increased emphasis on pharmacological symptom control, replacing the historical focus on the act of caring for the dying, which once was regarded as the hallmark of the hospice movement. Recent literature arguing for the expansion of palliative medicine does certainly place emphasis on the importance of symptom management, not just at end of life, but throughout the illness trajectory. It should be noted, though, that other elements of care, 
such as support with decision-making and future planning, quality of communication and spiritual assessment are also detailed as being key to the delivery of effective palliative care (Hughes \& Smith, 2014; Strand, Mansel, \& Swetz, 2014).

It is, perhaps, because of this broadened focus that doctors within palliative care settings might (somewhat paradoxically) also find themselves prone to the well-established critique as to whether a more holistic approach within medicine results in an extension of the profession's sphere of control beyond that of individuals' physical bodies, to also encompass the way that they think, feel and behave (Armstrong, 1986; Illich, 1975). Of course, such criticisms do, to some extent, leave palliative care physicians in the unenviable position in which they are open to criticism of medical imperialism if they attempt to engage in more holistic care or medical reductionism if they do not.

When considered in the context of dying roles, however, these observations do point to a broadening of medical (and institutional) control over what were once personal elements of the dying process. Furthermore, they are suggestive of a propensity (albeit wellintentioned) among palliative care professionals to emphasise the centrality of their service in ensuring the successful enactment of dying roles (Emanuel et al., 2007; Parker-Oliver, 2000). While such positions are not necessarily problematic (and might often be helpful), they do bring with them the risk of obscuring the strengths and expertise that patients and their informal care networks might already possess in the management of their own needs (Hughes, 2015). 


\section{The 'good death' and the 'good patient'}

'The good death' according to Kellehear (2007b, p. 90) is one which "conforms to the wider community expectation of making death as positive and meaningful as possible to as many people as possible." This definition acknowledges the powerful influence that societal norms and expectations have in shaping and framing preferences and beliefs around the dying process. While death may be personally experienced by the dying person, the meanings and associated practices surrounding death are, in essence, a product of society. As such, health professionals, family members and the broader community all exert a powerful influence in the construction of what may be regarded as 'good' and conversely 'bad' deaths (Kellehear, 2007b; McNamara, 2004). There is now a large body of published literature stemming from a variety of health professions either directly or indirectly addressing the concept of, or strategies for, the achievement of 'the good death'(Granda-Cameron \& Houldin, 2012). This is, perhaps, reflective of a perception among health professions regarding their critical role in enabling a positive dying experience and arguably evidence of their efforts to 'own' aspects of it.

Whatever the intention behind this strong interest in defining and fostering 'the good death', such efforts bring with them the risk of nurturing a professionally dominated approach to the management of dying. Furthermore, if not managed well, the large number of professionals vying for a centre stage position in one or more acts of the drama of dying, runs the unintended, but not insignificant, risk of 
fostering role confusion and diminishment for the dying person and his or her loved ones.

As cultural understandings of death and dying have evolved over time, so too have contemporary beliefs and practices concerning what constitutes the good death. In their review of the literature regarding 'the good death', Proulx \& Jacelon (2004, p. 118) identified a number of common themes including: death with dignity, peacefulness, physical comfort, autonomy, preparedness, connectedness with loved ones, awareness, discretion, meaning and acceptance. Almost all of these themes have in common a requirement for the dying individuals to be both accepting of and at peace with their dying in order for the good death to be achieved. This observation is further evidenced by the findings of Zimmermann (2012) whose recent discourse analysis of palliative care literature found that 'acceptance' of dying was regarded as a necessary precursor to effective contemporary end-of-life care. Zimmermann (2012) highlights that, while acceptance of death is welcomed by health workers, perceived denial of death will be met with professional resistance and offers of psychological assistance. While, at face value, the serene acceptance of death may seem to be in the best interests of both individuals who are dying and their loved ones, critics point to concerns regarding the influence of such strong ideological beliefs in acting as a mechanism of social control. They argue that 'good deaths' are typically those which are judged to be socially desirable by the professional caregivers of the dying and that deaths that occur outside of these professionally derived norms are considered problematic (Hart et al., 1998; McNamara, Waddell, \& 
Colvin, 1994). Patients who adhere to the parameters of 'the good death' are considered 'good patients' but those who do not are labelled as being at risk of a 'bad death' and will be gently cajoled into beliefs and behaviours that are compliant with the good death model (Hart et al., 1998; Li, 2004; Li \& Arber, 2006). The end result of this is the construction of a dying process that is reliant on new biomedical technologies and specialist professional input, thus further reinforcing professional power (Hart et al., 1998; Kellehear, 2007a; McNamara et al., 1994; Timmermans, 2005). In essence, the ideology of 'the good death' serves as a new form of social control over dying people, constraining their choices and tightly scripting the nature of their dying (Hart et al., 1998). It is, perhaps, in response to this that an increasing number of academics and clinicians have made calls for greater flexibility in any interpretation of the good death (Hardy \& Good, 2014; Scarre, 2012; Walters, 2004).

Considered in the context of role change, the social value placed upon the attainment of a 'good death' places powerful pressure upon the dying to swiftly and effortlessly transition to normalised expectations and behaviours associated with the dying role. For many, these expectations will be in stark contrast to the social expectations surrounding the illness roles which they had until recently held (Parker-Oliver, 2000). The discourse of illness has long been recognised as being laden with war metaphors framing social expectations of the illness role as one in which an individual must fight and battle against the enemy that is their disease (Sontag, 1979). However, once doctors determine this battle has been lost, an expectation then falls upon the dying individual to relinquish their 
soldier-like characteristics and instead adopt a veneer of calm acceptance of the approach of their death. Those who resist this new identity may find themselves labelled as 'bad patients' at risk of a 'bad death' and thus be coaxed and encouraged to play the role expected of them.

\section{The 'good death' and the 'good carer'}

Idealised conceptualisations of the good death can also place significant pressure upon informal carers of the dying (such as family members and friends), particularly in relation to popular notions that the good death ought to occur at home (Pollock, 2015). Research suggests that up to two-thirds of the general public identify home as their preferred place of death (Higginson \& Sen-Gupta, 2000; Leadbeater \& Garber, 2010) and approximately 80 percent of patients who have never been admitted to a hospice wish to die at home (Arnold, Finucane, \& Oxenham, 2015). Such beliefs, while not unreasonable, can result in a strong sense of obligation upon family members and friends of the dying to support a home death. The enactment of these unfamiliar caring roles can result in considerable emotional, physical (and sometimes financial) burden on both the carer and the dying individual, particularly if the process of dying proves lengthy or is accompanied by issues such as intractable pain (Pollock, 2015). It is unsurprising, therefore, that there are increasing calls for preferred place of death to be revisited on an ongoing basis as patients near end of life, so as to ensure that changing preferences are acknowledged and (where possible) acted on (Arnold et al., 2015; Pollock, 2015). 


\section{Contemporary cultural scripts for death and dying}

Societal discourse serves a powerful and pervasive function in constructing contemporary understandings of what can be considered 'normal' end-of-life roles and thus in shaping the cultural scripts through which these roles are played out. One particularly powerful form of discourse is metaphor. Metaphor describes the process through which people talk and think about one thing in terms of something else. Doing so serves as a lens through which we can mediate what is known and what is not known, thus shaping our conscious and unconscious understanding of the world in which we live (Ritchie, 2013). Metaphors surrounding dying and death tend to fall into one of two broad categories. The first of these categories conveys images of struggle and heroism and the second attempts to soften and even nullify death. Both sets of metaphors act to serve the interests of the living by supporting them in denying the impact of death.

Metaphors equating the dying process to a heroic struggle are well documented in academic literature and are clearly observable both within the modern media and general parlance. The seminal work of Susan Sontag (1979) revealed the prevalence of war metaphors in relation to cancer. Words such as 'battle', 'fight', 'bombard' or 'eradicate' were noted as having a strong influence in shaping understandings of the disease and its management. Several other researchers report a similar propensity towards the use of military metaphor in cancer treatment, highlighting concerns that such language promotes the masculinised and paternalistic management of the disease at the expense of a focus on alternative illness 
experiences (Byrne, 2008; Lupton, 1994; Penson, Schapira, Daniels, Chabner, \& Lynch, 2004). Seale (2001) extends this picture to include metaphors reflective of sporting struggle in relation to cancer. However, he challenges suggestions that 'struggle language' is universally problematic in cancer discourse, arguing that stories of struggle, triumph and personal growth (even in defeat) can have a positive influence on the illness experience.

It is important to note that the vast majority of the "heroic struggle metaphors' focus on efforts to overcome a disease. It is unusual for them to be used to describe the process of dying (i.e. 'heroic dying'), until the actual point of death at which stage an individual will be noted to have 'lost his or her battle'. As such they are, to a large extent, being used to describe what Parsons (1951) labelled the 'sick role' since these metaphors relate to efforts to curtail death, rather than the phenomena of death or dying per se. To this end they serve the interests of the living by depicting death as something that can and should be avoided. In doing so, this type of metaphor clouds the distinction between sick and dying roles by framing the role of the dying person as resisting death at all costs.

The second major cluster of dying metaphors encompasses those which act to soften, negate or hide death and dying. Phrases such as 'passed away', 'deceased' and 'expired' all serve this purpose by fostering a picture of death as being peaceful and calm (Durkin, 2003; Hayslip, 2003). 'Journey' metaphors that are often employed to describe illness and dying have rich, positive connotations, evoking images of holidays and adventures (Harrington, 2012; Reisfield \& Wilson, 2004). These metaphors act as a convenient 
mechanism to avoid the confrontation of dying as a dirty, messy and potentially distressing experience (Lawton, 1998). Consequently, they serve to reinforce the societal expectation that dying is something that should be sanitized, whispered about behind closed doors or, if possible, not discussed at all.

Both the electronic and print media also have a profound influence in reinforcing social scripts targeted at negating the reality of death. While representations of dying are commonplace within both popular fiction and mainstream news, the notion of any sense of 'normalness' around dying tends to be obscured, with dying instead dramatized as being either a violent, tragic or heroic event. As a result, death is conceptually distanced from the general public, through its characterisation as something that happens to 'someone else' who was unfortunate enough to find him or herself in a situation resulting in his or her demise. For example, within mainstream news media, little attention is afforded to 'ordinary deaths' among 'ordinary people' (excluding, perhaps, a brief mention in the obituaries section of a newspaper). Air time or column space tends to be reserved for the death of the political, economic or cultural elites or to report on deaths that occur due to extraordinary or violent circumstances (particularly if the deceased might be seen as vulnerable, such as children or the elderly) (Hanusch, 2010; Walter, Littlewood, \& Pickering, 1995).

Where potential exists for a particular death narrative to strike an empathetic chord, the depiction of death will most likely be either hidden from view or, at least, softened so as not to create discomfort. Thus, the potential for heightened death anxiety in the media is 
typically counterbalanced with inbuilt mechanisms that obscure death, in effect suppressing thoughts and / or fears about the process (Hayslip, 2003). This is, perhaps, most observable within cinematic depictions of death and dying, in which focus is typically placed on the event of death, rather than the process of dying, with the death itself implied rather than shown (McInerney, 2009).

These media portrayals of death again offer explanatory value through the way in which they nurture popular understandings of dying as a process which is under the control of the living. The problem with these depictions, however, is that they differ significantly from the actual dying process itself which can often be marked by poorly managed symptoms, bodily decline, distress and even mundanity (Kellehear, 2009b; Lawton, 1998). This results in feelings of confusion, inadequacy, isolation and even alienation among individuals whose experiences of dying do not coincide with the popularised expectation of the good death. While these different experiences could potentially expose an incongruence in the contemporary drama of dying, such incongruence is hidden from the broader societal audience by tightly woven, socially constructed scripts requiring an acceptance of the dying process by the dying themselves.

\section{Conclusion and Implications}

This narrative review of the literature has outlined the socially constructed nature of the various roles enacted within the drama of dying. It has highlighted a pattern throughout history in which dying 
has been depicted as being under the control of dominant societal groups, thus fostering tight adherence to a set of dying scripts which serve the needs of the living above and beyond those of the dying.

The centrality of powerful societal institutions in fostering a professional dominance over the dying process has been detailed. Particular attention has been paid to the way in which professional bodies regulate transitions into and out of dying roles and elevate the importance of aspects of dying that relate to their perceived domain of expertise (and hence, control) over others. The authors have argued that this professional influence over the drama of dying has resulted in the diminishment of the role of the dying person into a position of relative obscurity. An examination of post-modern discourse and media portrayals of dying has also revealed a tendency to soften (and hide) the dying experience or, alternatively, sensationalise it such that it feels distant and irrelevant to most members of society. This has a laid the foundation upon which an ongoing disengagement with dying among the general public has been nurtured, thereby paving the way for even further professional control over the dying process.

While this 'façade of control' over dying benefits health professionals in terms of emphasising the importance of their role and (arguably) assists the general public by negating death anxiety, it comes at a particular cost to those who are dying and their informal carers. To quote Scarre (2012, p. 1084), "It looks as though we die tranquilly only by pulling the wool over our own eyes." In essence, the tendency towards contemporary dying scripts which emphasise a 'good death' as one in which the dying person achieves a sense of 
serenity and acceptance, has contributed to a silencing of dying people with regard to experiences of and potential frustrations with a process of dying that do not conform to this popularised ideology. These findings highlight the need for further research that offers insights into the perspectives of dying roles from the viewpoint of dying people themselves. As part of this, specific attention should be paid to the experiences of people who undergo marginalised forms of dying and who, as a result, might not currently be afforded the opportunity for the enactment of dying roles of any sort. 


\section{$\underline{\text { Reference List }}$}

Aries, P. (1974). Western attitudes toward death. (H. Weaver, Trans.). London: John Hopkins University Press.

Aries, P. (1981). The hour of our death. (H. Weaver, Trans.). New York: Alfred A. Knopf.

Armstrong, D. (1986). The problem of the whole-person in holistic medicine. Holistic Medicine., 1 , 27-36.

Arnold, E., Finucane, A. M., \& Oxenham, D. (2015). Preferred place of death for patients referred to a specialist palliative care service. BMJ supportive \& palliative care, 5(3), 294-296. doi:10.1136/bmjspcare-2012-000338

Bakanic, V., Singleton, M., \& Dickinson, G. E. (2016). Hospice Attitudes of Physicians and Nurses: A Pilot Study. American Journal of Hospice and Palliative Medicine, 33(1), 34-40. doi:10.1177/1049909114552124

Beecher, H. K., Adams, R. D., \& Barger, C. (1984). A definition of irreversible coma. Report of the Ad Hoc Committee of the Harvard Medical School to examine the definition of brain death. JAMA: The Journal of the American Medical Association, 252(5), 677-679. doi:10.1001/jama.1984.03350050065031;10.1001/jama.252.5.677;

Bingley, A. F., McDermott, E., Thomas, C., Payne, S., Seymour, J. E., \& Clark, D. (2006). Making sense of dying: A review of narratives written since 1950 by people facing death from cancer and other diseases. Palliative Medicine, 20(3), 183-195.

Bowman, F. P. (1965). Montaigne: essays. London: E. Arnold.

Bruno, M., Ledoux, D., \& Laureys, S. (2009). The dying human in biomedicine. In A. Kellehear (Ed.), The study of dying. From autonomy to transformation. (pp. 51-75). Cambridge: Cambridge University Press.

Byrne, M. (2008). Spirituality in palliative care: what language do we need? International Journal of Palliative Nursing, 14(6), 274-280.

Dahlin, C. (2013). Clinical practice guidelines for quality palliative care. Retrieved from Pittsburgh:

Doka, K. J. (2003). The death awareness movement. In C. D. Bryant (Ed.), Handbook of death \& dying (pp. 50-56). Thousand Oaks, California: Sage Publications.

Durkin, K. F. (2003). Death, dying, and the dead in popular culture. In C. D. Bryant (Ed.), Handbook of death \& dying (pp. 43-49). Thousand Oaks, Calif: Sage Publications.

Elias, N. (1985). Loneliness of the Dying. Oxford: Basil Blackwell Ltd.

Emanuel, L., Bennett, K., \& Richardson, V. E. (2007). The dying role. Journal of Palliative Medicine, $10(1), 159-168$.

Field, D. (1996). Awareness and modern dying. Mortality, 1(3), 255-265. doi:10.1080/13576279609696247

Floriani, C. A., \& Schramm, F. R. (2012). Routinization and medicalization of palliative care: Losses, gains and challenges. Palliative and Supportive Care, 10(4), 295-303. doi:10.1017/S1478951511001039

Froggatt, K. (1997). Rites of passage and the hospice culture. Mortality, 2(2), 123-136. doi:10.1080/713685862

Gittings, C. (2009). The art of dying. In A. Kellehear (Ed.), The study of dying. From autonomy to transformation. (pp. 163-187). Cambridge: Cambridge University Press.

Glaser, B. G., \& Strauss, A. L. (1965). Awareness of dying. Chicago: Aldine Transaction.

Glaser, B. G., \& Strauss, A. L. (1968). Time for dying. Chicago: Aldine Transaction.

Goffman, E. (1959). The presentation of self in everyday life. New York: Doubleday.

Granda-Cameron, C., \& Houldin, A. (2012). Concept Analysis of Good Death in Terminally Ill Patients. American Journal of Hospice and Palliative Medicine, 29(8), 632-639. doi:10.1177/1049909111434976

Hanusch, F. (2010). Representing Death in the News: Journalism, Media and Mortality. Basingstoke: Palgrave Macmillan Ltd. 
Hardy, J. R., \& Good, P. (2014). A good death in hospital. Internal medicine journal, 44(4), 313-314. doi:10.1111/imj.12378

Harrington, K. J. (2012). The use of metaphor in discourse about cancer: a review of the literature. Clinical Journal of Oncology Nursing, 16(4), 408-412. doi:10.1188/12.CJON.408-412

Hart, B., Sainsbury, P., \& Short, S. (1998). Whose dying? A sociological critique of the 'good death'. Mortality, 3(1), 65-77. doi:10.1080/713685884

Hayslip, B. (2003). Death denial. Hiding and camouflaging death. In C. D. Bryant (Ed.), Handbook of death \& dying (pp. 34-42). Thousand Oaks, California: Sage Publications.

Higginson, I. J., Costantini, M., Silber, E., Burman, R., \& Edmonds, P. (2011). Evaluation of a new model of short-term palliative care for people severely affected with multiple sclerosis: A randomised fast-track trial to test timing of referral and how long the effect is maintained. Postgraduate Medical Journal, 87(1033), 769-775. doi:10.1136/postgradmedj-2011-130290

Higginson, I. J., \& Sen-Gupta, G. J. A. (2000). Place of care in advanced cancer: A qualitative systematic literature review of patient preferences. Journal of Palliative Medicine, 3(3), 287300. doi:10.1089/jpm.2000.3.287

Howarth, G. (2000). Dismantling the boundaries between life and death. Mortality, 5(2), 127-138. doi:10.1080/713685998

Hughes, M. E. (2015). A Strengths Perspective on Caregiving at the End-of-life. Australian social work, 68(2), 156-168.

Hughes, M. T., \& Smith, T. J. (2014). The Growth of Palliative Care in the United States. Annual review of public health, 35, 459-475. doi:10.1146/annurev-publhealth-032013-182406

Illich, I. (1975). Medical nemesis: the expropriation of health. London: Lothian Pub. in association with Calder \& Boyars.

James, N., \& Field, D. (1992). The routinization of hospice: Charisma and bureaucratization. Social Science \& Medicine, 34(12), 1363-1375. doi:10.1016/0277-9536(92)90145-G

Kellehear, A. (2007a). The end of death in late modernity: An emerging public health challenge. Critical Public Health, 17(1), 71-79. doi:10.1080/09581590601156365

Kellehear, A. (2007b). A social history of dying. New York: Cambridge University Press.

Kellehear, A. (2009a). On dying and human suffering. Palliative Medicine, 23(5), 388-397. doi:10.1177/0269216309104858

Kellehear, A. (2009b). The study of dying. From autonomy to transformation. Cambridge: Cambridge University Press.

Kubler-Ross, E. (1969). On death and dying. What the dying have to teach doctors, nurses, clergy and their own families. Abingdon: Routledge.

Lawton, J. (1998). Contemporary hospice care: The sequestration of the unbounded body and 'dirty dying'. Sociology of Health and Illness, 20(2), 121-143. doi:10.1111/1467-9566.00094

Leadbeater, C., \& Garber, J. (2010). Dying for change. London: DEMOS.

Li, S. (2004). 'Symbiotic niceness': constructing a therapeutic relationship in psychosocial palliative care. Social Science \& Medicine, 58(12), 2571-2583. doi:10.1016/j.socscimed.2003.09.006

Li, S., \& Arber, A. (2006). The Construction of Troubled and Credible Patients: A Study of Emotion Talk in Palliative Care Settings. Qualitative Health Research, 16(1), 27-46. doi:10.1177/1049732305284022

Lupton, D. (1994). Femininity, responsibility and the technological imperative: discourses on breast cancer in the Australian Press. International Journal of Health Services., 24(1), 73-89.

Lynch, K. D. (2007). Modeling Role Enactment: Linking Role Theory and Social Cognition. Journal for the Theory of Social Behaviour, 37(4), 379-399. doi:10.1111/j.1468-5914.2007.00349.x

Lyons, M. B. K. D., \& M. Bakitas, K. D. L. (2009). Effects of a palliative care intervention on clinical outcomes in patients with advanced cancer: The Project ENABLE II randomized controlled trial. JAMA : the journal of the American Medical Association, 302(7), 741.

McGrath, P., Moore, A., McNaught, M., Palmer, G., Greene, A., \& Atkinson, D. (2005). Another form to fill in! Clients' reflections on the hospice use of questionnaires. Supportive Care in Cancer, 13(9), 691-701. doi:10.1007/s00520-005-0795-6

McInerney, F. (2009). Cinematic visions of dying. In A. Kellehear (Ed.), The study of dying. From autonomy to transformation. (pp. 211-232). Cambridge: Cambridge University Press. 
McNamara, B. (2004). Good enough death: autonomy and choice in Australian palliative care. Social Science \& Medicine, 58(5), 929-938. doi:10.1016/j.socscimed.2003.10.042

McNamara, B., Waddell, C., \& Colvin, M. (1994). The institutionalization of the good death. Social Science \& Medicine, 39(11), 1501-1508. doi:10.1016/0277-9536(94)90002-7

Palliative Care Australia. (2005). Standards for providing quality palliative care for all Australians. 4th Edition. Canberra: Palliative Care Australia.

Parker-Oliver, D. (2000). The social construction of the "dying role" and the hospice drama. Omega, 40(4), 493-512.

Parsons, T. (1951). The social system. Glencoe, Ill Free Press.

Penson, R. T., Schapira, L., Daniels, K. J., Chabner, B. A., \& Lynch, J. T. J. (2004). Cancer as metaphor. The oncologist, 9(6), 708-716. doi:10.1634/theoncologist.9-6-708

Pollock, K. (2015). Is home always the best and preferred place of death? BMJ-British Medical Journal, 351, h4855. doi:10.1136/bmj.h4855

Proulx, K., \& Jacelon, C. (2004). Dying with dignity: the good patient versus the good death. The American journal of hospice \& palliative care, 21(2), 116-120. doi:10.1177/104990910402100209

Reisfield, G. M., \& Wilson, G. R. (2004). Use of metaphor in the discourse on cancer. Journal of clinical oncology : official journal of the American Society of Clinical Oncology, 22(19), 4024-4027. doi:10.1200/JCO.2004.03.136

Ritchie, L. D. (2013). Metaphor. Cambridge: Cambridge University Press.

Scarre, G. (2009). Dying and philosophy. In A. Kellehear (Ed.), The study of dying. From autonomy to transformation. (pp. 147-162). Cambridge: Cambridge University Press.

Scarre, G. (2012). Can there be a good death? Journal of evaluation in clinical practice, 18(5), 10821086. doi:10.1111/j.1365-2753.2012.01922.x

Seale, C. (1998). Constructing death: the sociology of dying and bereavement. Cambridge, England: Cambridge University Press.

Seale, C. (2001). Sporting cancer: struggle language in news reports of people with cancer. Sociology of Health and Illness, 23(3), 308-329.

Sontag, S. (1979). Illness as metaphor. London: Allen Lane.

Stephenson, J. S. (1985). Death, grief and mourning: Individual and social realities. New York.: Free Press.

Strand, J. J., Mansel, K., \& Swetz, K. M. (2014). The growth of palliative care. Minnesota Medicine, June.

Temel, J. S., Greer, J.A., Muzikansky, A., Gallagher, E.R., Admane, S., Jackson, V.A, . . Lynch, T.J. (2010). Early Palliative Care for Patients with Metastatic Non-Small-Cell Lung Cancer. The New England Journal of Medicine, 363(8), 733-742. doi:http://dx.doi.org/10.1056/NEJMoa1000678

Timmermans, S. (2005). Death brokering: constructing culturally appropriate deaths. Sociol Health Illn, 27(7), 993-1013. doi:10.1111/j.1467-9566.2005.00467.x

Turner, R. H. (1956). Role-Taking, Role Standpoint, and Reference-Group Behavior. The American Journal of Sociology, 61(4), 316-328. doi:10.1086/221763

Turner, R. H. (1990). Role Change. Annual Review of Sociology, 16(1), 87-110. doi:10.1146/annurev.so.16.080190.000511

Turner, V. (1974). Dramas, fields and metaphors: Symbolic action in human society. New York.: Cornell University Press.

van Gennep, A. (1909/1960). The rites of passage. Chicago: University of Chicago Press.

Walter, T. (1994). The revival of death. London: Routledge.

Walter, T. (2003). Historical and cultural variations on the good death. BMJ Quality \& Safety, 327, 218-220.

Walter, T., Littlewood, J., \& Pickering, M. (1995). Death in the News: The Public Invigilation of Private Emotion. Sociology, 29(4), 579-596. doi:10.1177/0038038595029004002

Walters, G. (2004). Is there such a thing as a good death? Palliative Medicine, 18(5), 404-408. doi:http://dx.doi.org/10.1191/0269216304pm908oa 
World Health Organisation. (2007). Definition of Palliative Care. Geneva: World Health Organisation.

Zimmermann, C. (2012). Acceptance of dying: a discourse analysis of palliative care literature. Social science \& medicine (1982), 75(1), 217-224. doi:10.1016/j.socscimed.2012.02.047

Zimmermann, C., Yuen, D., Mischitelle, A., Minden, M. D., Brandwein, J. M., Schimmer, A., . . . Rodin, G. (2013). Symptom burden and supportive care in patients with acute leukemia. Leukemia Research, 37(7), 731-736. doi:10.1016/j.leukres.2013.02.009 


\section{APPENDIX 1}

Summary of search terms and record of hits and relevant sources of literature

\begin{tabular}{|c|c|c|c|}
\hline Database & Search Terms & $\begin{array}{c}\text { Hits } \\
\text { Retrieved }\end{array}$ & $\begin{array}{c}\text { Relevant on title } \\
\text { and abstract } \\
\text { review }\end{array}$ \\
\hline \multirow[t]{4}{*}{ CINAHL } & $\begin{array}{l}\text { 1. "Terminally Ill Patients" OR "Terminal Care" } \\
\text { OR "Palliative Care" OR "Hospice*" OR } \\
\text { "Hospice Care" OR "Hospice and palliative } \\
\text { nursing" OR "Cancer Care Facilities" OR "life } \\
\text { limiting illness" OR "Hospice Patients" }\end{array}$ & 39088 & \\
\hline & $\begin{array}{l}\text { 2. "role*” OR "sick role" OR "sick roles" OR } \\
\text { "family role" OR "family roles*" OR "self } \\
\text { concept" OR occupation* OR identit* OR } \\
\text { "social identity" OR "identity crisis" }\end{array}$ & 294770 & \\
\hline & $\begin{array}{l}\text { 3. "change*” OR "social change" OR "social } \\
\text { changes" OR "role change" OR "role changes" } \\
\text { OR "transition*" OR "health transition" OR } \\
\text { "loss*" OR "adapt*" OR "adaptation } \\
\text { psychological" OR "adaptation occupational" } \\
\text { OR "life experiences" OR "LIFE CHANGE } \\
\text { EVENTS" OR "SOCIAL ADJUSTMENT" OR } \\
\text { "social adjustments" OR "Attitude to illness" } \\
\text { OR "Attitude to death" OR "Attitude to health" } \\
\text { OR "Life purpose" OR "psychosocial aspects of } \\
\text { illness" }\end{array}$ & 304381 & \\
\hline & 1,2,3 COMBINED (with AND) & 1108 & 73 \\
\hline \multirow[t]{4}{*}{ Medline } & $\begin{array}{l}\text { 1. "terminal care" OR "end of life care" OR } \\
\text { PALLIATIVE OR HOSPICE* OR } \\
\text { "bereavement care" OR "TERMINALLY ILL" } \\
\text { OR "life limiting illness" }\end{array}$ & 93871 & \\
\hline & $\begin{array}{l}\text { 2. "role*” OR "sick roles" OR "sick role" OR "self } \\
\text { concept" OR occupation* OR identit* }\end{array}$ & 184039 & \\
\hline & $\begin{array}{l}\text { 3. "change*" OR transition* OR loss* OR adapt* } \\
\text { OR "patient perspective*" OR lived } \\
\text { experience* OR experience* OR "LIFE } \\
\text { CHANGE EVENTS" OR "life experience" OR } \\
\text { "life experiences" OR "adaptation } \\
\text { psychological" OR "health transition" OR } \\
\text { "SOCIAL ADJUSTMENT" OR "social } \\
\text { adjustments" OR "behaviors adaptive" OR } \\
\text { "behavior adaptive" OR "ATTITUDE TO } \\
\text { HEALTH" }\end{array}$ & 1062543 & \\
\hline & 1,2,3 COMBINED (with AND) & 1155 & 45 \\
\hline \multirow[t]{2}{*}{ PsychInfo } & $\begin{array}{l}\text { 1. "terminally ill patients" OR "terminal cancer" } \\
\text { OR "hospice*" OR "palliative care" OR "death } \\
\text { and dying" }\end{array}$ & 10273 & \\
\hline & $\begin{array}{l}\text { 2. "roles" OR "role conflict" OR "role conflicts" } \\
\text { OR "role perception" OR "role expectations" } \\
\text { OR "role satisfaction" OR "role taking" OR } \\
\text { "self concept" OR "sense of coherence" OR } \\
\text { "self congruence" OR "self perception" OR }\end{array}$ & 120669 & \\
\hline
\end{tabular}




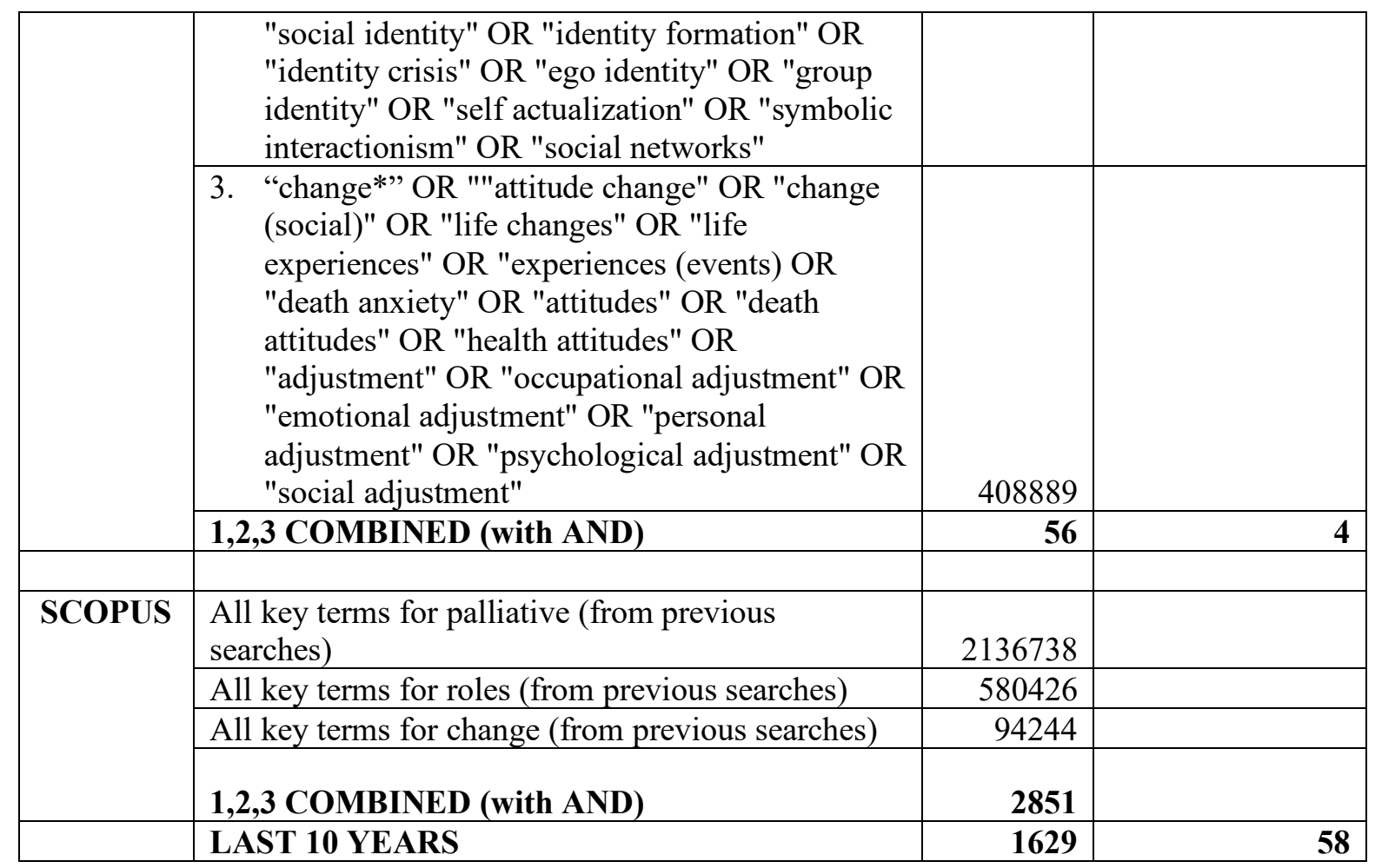

